\title{
Política de propriedade intelectual em medicamentos: uma visão do início da década de 2000
}

DOI: 10.3395/reciis.v2i2.191pt

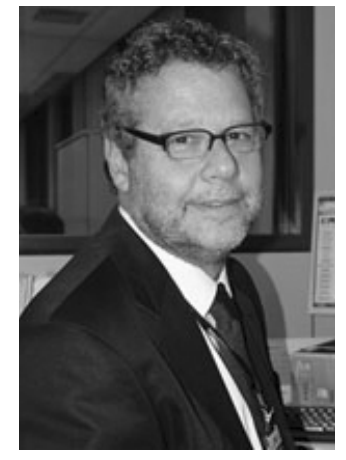

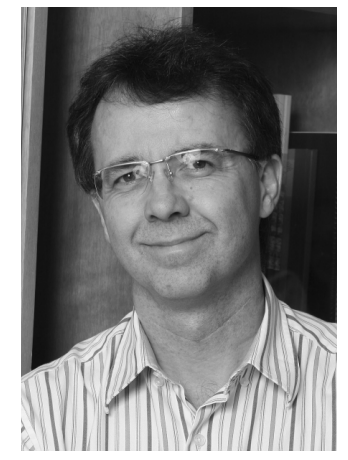

Sergio SallesFilho

Departamento de Política Científica e Tecnológica, Universidade Estadual de Campinas, Campinas, Brasil sallesfi@ige.unicamp.br

\section{Antonio Márcio Buainain \\ Instituto de Economia, Universidade Estadual de Campinas, Campinas, Brasil \\ buainain@eco.unicamp.br}

\section{Maria Beatriz Bonacelli}

Departamento de Política Científica e Tecnológica, Universidade Estadual de Campinas, Campinas,

Brasil

bia@ige.unicamp.br

\section{Marcos Paulo Fuck \\ Departamento de Política Científica e Tecnológica, Universidade Estadual de Campinas, Campinas, Brasil \\ fuck@ige.unicamp.br}

\section{Resumo}

O artigo pretende fazer uma análise da política de propriedade intelectual no campo da saúde, enfatizando o programa de produção e distribuição de antiretrovirais e o mercado de genéricos. Para tanto é analisado o processo de articulação e implementação de política de propriedade intelectual nesse setor. O trabalho, do ponto de vista metodológica, privilegia a análise dos dados relativos à estruturação do mercado de medicamentos e na análise dos impactos tanto da nova institucionalidade quanto das políticas de propriedade intelectual desenvolvidas a partir do Ministério da Saúde na primeira metade da década de 2000.

\section{Palavras-chave}

propriedade intelectual; política; saúde; medicamentos 


\section{Introdução}

A reforma da legislação relativa à propriedade intelectual que teve lugar no Brasil na segunda metade dos anos 1990, uma decorrência do Acordo TRIPs, pode ser vista como ensejando diferentes oportunidades e constrangimentos. Estes podem se articular ao tipo de proteção (no campo da propriedade industrial, se patentes, marcas, indicações geográficas; se direitos de autor em um sentido mais amplo ou, mais especificamente, de programas de computador; no campo das proteções sui generis, se proteção de cultivares e proteção à diversidade biológica), ou à capacidade científica e tecnológica nacional em gerar novo e útil conhecimento a ser protegido e em utilizar as informações relativas às invenções que são objeto da proteção (Carvalho \& Pessanha 2001, Carvalho 2002a).

Deve ser ressaltado que uma característica importante do Acordo TRIPs foi a de vincular a proteção intelectual ao comércio exterior. Tradicionalmente, especialmente a partir da Convenção de Paris de 1883, os acordos na área de propriedade intelectual vinculavam a propriedade intelectual ao desenvolvimento tecnológico e econômico dos países partícipes de tais acordos. Essa mudança de ênfase apresenta algumas questões relevantes. Uma delas é a de ampliar as assimetrias entre países de maior desenvolvimento relativo em comparação aos demais. Essas assimetrias tendem a se repetir no contexto dos países em desenvolvimento. Assim, os impactos podem ser ainda mais regressivos para as economias que não dispõem de infra-estrutura e capacitação técnica e científica, além de industrial, para assimilar tecnologias que são mais fortemente protegidas a partir do Acordo TRIPs (Juma 1999, Aded 2001, Dutfield 2001).

Alguns autores, como Coriat (2002), entendem que as mudanças em curso na legislação dos direitos de propriedade intelectual levaram à criação de barreiras de natureza institucional que reservam o uso exclusivo dos novos conhecimentos para o benefício das grandes empresas multinacionais dos países centrais, ao mesmo tempo que esse direito exclusivo é imposto, através de acordos internacionais, aos mercados internos dos países em desenvolvimento. Entretanto, o Acordo TRIPs apresenta duas características relevantes que podem ser entendidas como positivas do ponto de vista dos países em desenvolvimento, tais como o Brasil. Como resultado do Acordo, foi criada uma instância multilateral para resolução de controvérsias, que passam a se dar através de painéis na Organização Mundial do Comércio (OMC). Outra característica relevante remete à manutenção da possibilidade de concessão de licenças compulsórias e utilização de importações paralelas. Esse é um ponto polêmico que remonta à própria Convenção de Paris de 1883, porém exercida ao longo de todo século XX. Possibilita ampliar a intervenção dos países signatários do Acordo TRIPs em matéria de flexibilização dos direitos de propriedade intelectual, sem todavia ferir este último Acordo (Aded 2001, Carvalho 2003).

A esses pontos soma-se uma nova estrutura de regulação de comércio internacional que restringe o emprego de políticas de incentivo à produção nacional nos moldes que nortearam o processo de industrialização de países em desenvolvimento, especialmente as de substituição de importações com base em subsídios diretos e fechamento dos mercados nacionais. As políticas de apoio à industrialização e ampliação da competitividade e a política científica e tecnológica tendem a incorporar a inovação no seu cerne, convergindo, de forma crescente, para as políticas de ciência, tecnologia e inovação. Neste contexto da política de inovação e industrial, a propriedade intelectual é um importante balizador, assim como uma instância que envolve ações específicas para ampliar os impactos positivos e reduzir o potencial constrangimento que as restrições derivadas do Acordo TRIPs possam causar no desenvolvimento tecnológico e nacional (Carvalho 2003).

Políticas específicas podem (e devem) ser desenvolvidas pelo Estado, particularmente a partir da base cientifica e tecnológica nacional. O Brasil apresenta um exemplo marcante de política de propriedade intelectual aplicada em setores específicos: a atuação da Fiocruz na polêmica envolvendo o coquetel de medicamentos do Programa de Aids do governo brasileiro. A Fiocruz, por intermédio da sua unidade de produção de fármacos, FarManguinhos, disponibilizou para o Ministério da Saúde a estrutura de custos dos remédios que compunham o coquetel de remédios utilizados no Programa de Aids, identificando as moléculas e a tecnologia necessária à sua produção. Cabe ressaltar que os remédios em questão não estavam cobertos pelo mecanismo previsto na Lei de Propriedade Industrial de 1996, de reconhecimento retroativo pelo prazo remanescente da proteção, denominado pipeline (Carvalho 2002b).

Na Fiocruz observou-se um novo padrão de organização da pesquisa: busca por parcerias privadas e compartilhamento de resultados proprietários. Concorre para tanto a busca de complementaridade de competências que seriam impossíveis de serem incorporadas numa única instituição de pesquisa ou agente econômico de capital nacional. A lógica de atuação da pesquisa pública pode estar centrada nos mercados nos quais se inserem seus resultados, sem que se perca de vista o mandato e a lógica de geração de conhecimentos técnicos e científicos (Salles-Filho et al. 2001).

Deve ser ressaltado que esse é um fenômeno que extrapola as fronteiras de países de menor desenvolvimento relativo. Países da OCDE alteraram o marco de referência da propriedade intelectual dos resultados da pesquisa desenvolvida em instituições de pesquisa pública ou por agentes privados apoiados por fundos públicos. As patentes de universidades norte-americanas experimentaram sensível crescimento a partir do Bayh-Dole Act, nos anos 1980, assim como foram alterados dispositivos na lei antitruste para ampliar o processo de transferência de tecnologia (e licenciamento de patentes) para o setor privado. No Brasil, a proposta de Lei de Inovação, cuja tramitação foi retomada no final de 2003 e sancionada em 2004, também prevê a flexibilização da legislação que regula as licitações públicas, permitindo a utilização 
do mecanismo de compras governamentais para o apoio às empresas inovadoras e facilitando a transferência de tecnologia do setor público para o privado (OECD 1999, Buainain 2004).

Entretanto, em que pese o sucesso da ação governamental em áreas específicas, ao longo da década de 1990, as remessas para o exterior como decorrência de contratos de transferência de tecnologia foram ampliadas fortemente. A exploração de patentes, que em 1990 representava US\$ 3 milhões, alcançou o patamar de US\$ 200 milhões em 1996 e 98. As remessas relativas aos contratos de fornecimento de tecnologia subiram de US\$ 32 milhões em 1990 para próximo de US\$ 600 milhões em 1998. Os serviços técnicos especializados justificaram remessas para o exterior da ordem de US\$ 1.400 milhões em 1998 e 99, contra US\$ 140 milhões em 1990 (Carvalho 2002a). São dados que permitem visualizar efeitos regressivos e custos importantes decorrentes da adoção de um padrão de proteção nos moldes acordados no TRIPs.

A estrutura de administração dos estatutos de proteção à propriedade intelectual também influi na efetividade da proteção. A capacidade de análise de solicitações de prioridades de invenção, de registros de marcas, de definição de indicações de procedência, de proteção de cultivares, de definição de mecanismos de acesso ao patrimônio genético associado aos conhecimentos tradicionais são elementos que ampliam ou deprimem os incentivos e constrangimentos propiciados pelo reconhecimento de direitos de propriedade intelectual, especialmente no contexto da reformulação ocorrida na década de 1990, como decorrência da assinatura do Acordo TRIPs (Barbosa 1999, Carvalho 2002a, b).

A gestão desses estatutos, quando desvinculada de referências de política de inovação e de apoio ao desenvolvimento econômico nacional, tende a se revestir de um caráter cartorial, enfatizando a emissão de documentos e certificados de proteção e de reconhecimento dos direitos garantidos nesses estatutos. Esse é um elemento central do Sistema de Propriedade Intelectual (e a recuperação de estruturas institucionais, tais como a do Instituto Nacional de Propriedade Industrial é uma prova candente dessa centralidade), que em nenhuma hipótese deve ser descartado. Todavia, a formulação e implantação de políticas de propriedade intelectual de caráter amplo, é requisito prévio para ampliar os efeitos positivos e reduzir os efeitos negativos do reconhecimento desses direitos. Entre esses efeitos positivos estão o estímulo à capacitação tecnológica, à inovação e à transferência de tecnologia. O próximo item discute em maiores detalhes as relações entre a nova forma de apropriação decorrente da mudança institucional pós-Trips e a capacitação nacional no desenvolvimento de fármacos.

\section{Política de propriedade industrial em medicamentos}

Tal como o mercado de sementes no Brasil, o de medicamentos foi fortemente impactado pela entrada em vigor do Acordo TRIPS. O país não reconhecia direitos de propriedade industrial (PI) sob a forma de patentes em medicamentos para produtos desde 1945 e para processo desde 1969. Deste ponto de vista, poder-se-ia até considerar como uma situação análoga à do mercado de sementes. Todavia, há distinções relativas à dinâmica concorrencial, à importância da presença de empresas transnacionais no mercado brasileiro, ao papel do Estado na $\mathrm{P} \& \mathrm{D}$, à peculiaridade das atividades de $\mathrm{P} \& \mathrm{D}$ (não) desenvolvidas pelas empresas nacionais, e, particularmente, ao fato de que o processo de adaptação dos medicamentos ao mercado nacional não implica na necessidade das empresas transnacionais manterem estruturas próprias de pesquisa ou desenvolvimento de produtos e processos ou em associação com instituições de pesquisa nacionais no país. Assim, o desenho de políticas públicas voltadas para o setor tende a se diferenciar das voltadas para o mercado de semente, assim como o papel da opinião pública em assuntos relativos à saúde humana é mais proeminente (Salles-Filho et al. 2001).

O mercado brasileiro pré Acordo TRIPS era composto de duas categorias principais: um de medicamentos de marcas protegidos por patentes em outros países e outro segmento que contemplava os medicamentos similares, aqueles não são protegidos por patentes e que eram vendidos pela sua denominação genérica ou sob nome comercial. Quando se discutia a nova Lei de Propriedade Industrial, no início dos anos 1990, ganhou força a perspectiva de igualmente se discutir a adoção de uma legislação que contemplasse os medicamentos genéricos, aqueles que se referem aos medicamentos com patente expirada e considerados em domínio público. Na realidade, era uma iniciativa baseada na legislação norte-americana, o Hacth-Waxman Act, de 1983, que, objetivando acelerar o processo de comercialização de medicamentos cujas patentes haviam se tornado domínio público (expiradas) promoveu a redução do prazo de registro desses medicamentos. A lógica da legislação era a de promover uma maior competição, através da alternativa de criação de um segmento no qual os custos associados ao registro e testes clínicos, assim como os relativos à publicidade $\mathrm{e}$ fixação de marcas não pressionassem os preços para cima (Hasenclever 2004)

No Brasil em 1993, portanto antes da legislação que regulamentaria os medicamentos genéricos, foi promulgado o Decreto 793/93, que exigia que o nome dos princípios ativos constasse das embalagens dos remédios comercializados no país. A expectativa era a de que aumentando o grau de informação tanto dos que prescreviam a medicação quanto dos seus usuários pudesse ser feita escolha entre medicamentos com o mesmo princípio ativo, ampliando a competição no mercado de medicamentos. Ou seja, um mecanismo de redução do impacto da estratégia de diferenciação de preço via publicidade e fixação de marcas.

Todavia, antes de promulgação da Lei de Propriedade Industrial a figura do medicamento genérico não existia, não sendo possível seu registro. A figura do medicamento genérico passou a ser reconhecida a partir da aprovação da Lei 9787/1999, estabelecendo-se uma 
institucionalidade semelhante à verificada em diversos países que reconhecem patentes para medicamentos (Hasenclever 2004).

Todavia, cabe discutir um pouco mais antes de se entrar nos impactos da política de genéricos no Brasil, quais os elementos que nortearam a política de medicamentos de uma forma geral no país. Nesse sentido, os constrangimentos e oportunidades derivados do Acordo TRPIS para medicamentos devem ser ressaltados na análise.

Coriat et al. (2003) chamam a atenção que o ambiente pré-TRIPS foi caracterizado, em nível mundial, pela possibilidade dos países de menor desenvolvimento relativo estabelecerem estruturas industriais nacionais a partir da estratégia de cópia de moléculas desenvolvidas por outros países. Os medicamentos derivados dessas moléculas eram ofertados no mercado nacional a preços compatíveis com os níveis de renda existentes nesses países. Mesmo nos países desenvolvidos que reconheceram direitos de propriedade intelectual para medicamentos, procuraram fazê-lo de forma tal que a proteção não recaísse sobre a molécula, mas sobre o processo. Dessa forma, outras trajetórias tecnológicas que permitissem chegar à molécula não seriam obstaculizadas pelo reconhecimento de direitos de propriedade intelectual, mantendo alternativas no processo de inovação em medicamentos.

Os autores em questão entendem que o quadro derivado do Acordo TRIPS alterou de tal forma a lógica de proteção relacionada à saúde que esta foi contemplada num conjunto de exceções de direitos, entre os quais a possibilidade de se licenciar compulsoriamente drogas em situações de emergência que colocassem em risco a vida humana. Outro ponto levantado pelos autores remete à estratégia utilizada pelos países em desenvolvimento com capacitação técnica, científica e industrial para a produção local de medicamentos.

Dessa forma, duas vertentes de política de propriedade intelectual em saúde foram estabelecidas. Uma referente à política de tratamento universal de portadores do vírus HIV e outra relativa à criação de um mercado nacional de medicamentos genéricos, como assinalado acima. A condição básica para o estabelecimento dessas políticas se assenta na capacidade nacional científica e tecnológica para manter uma trajetória de cópia de produtos desenvolvidos por outros países e protegidos por patentes. Antes do Acordo TRIPS, essa trajetória era viável e legal no quadro institucional então vigente. Todavia, essa capacitação científica e tecnológica depende da capacitação industrial para produzir tais medicamentos.

Em relação ao tratamento da epidemia de aids, criou-se um quadro internacional interessante. Por um lado os países desenvolvidos, destacando-se os Estados Unidos, passaram a criar constrangimentos aos países em desenvolvimento que optassem pela estratégia de utilização de cláusula de licenciamento compulsório para os anti-retro-vivais (ARV) utilizados no tratamento de portadores de HIV, com sua produção sob a forma de medicamentos genéricos. Por outro lado, países que embora não tendo feito uso das flexibilidades do Acordo TRIPS estabeleceram políticas de propriedade intelectual visando contornarem os constrangimentos impostos pelas legislações de PI objetivando que implementaram.

Coriat et al. (2003) mostram que essas políticas de saúde pública em relação à epidemia da aids têm como base a redução dos custos do programa de distribuição de drogas, visando a manter sua universalidade. Deste ponto de vista, a utilização de princípios ativos os mais baratos possíveis passou ao ser ponto fundamental da referida política. E também criou outro tipo de articulação: o fornecimento de princípios ativos deveria se dar a partir dos países que usaram as flexibilidades do TRIPS em termos do não reconhecimento de direitos de propriedade intelectual para drogas já existentes. Duas premissas importantes desse tipo de política são: manutenção do livre comércio internacional dos princípios ativos e desenvolvimento de capacidade interna de produção desses princípios ativos.

Do ponto de vista dos preços, os autores entendem que a política de produção de ARVs nos países em desenvolvimento, tais como o Brasil, tiveram impacto positivo. Não só baixaram os preços dos medicamentos utilizados nos programas de distribuição de ARVs genéricos, como também essas mesmas drogas quando vendidas protegidas por patentes também sofreram baixas em seus preços, tendendo a convergir os preços dos medicamentos genéricos e sob proteção.

Essas políticas puderam ser desenvolvidas num contexto internacional no qual novos atores sociais ganharam proeminência e tiveram papel relevante na pressão sobre organismos internacionais, empresas farmacêuticas transnacionais e, particularmente, sobre o governo norte-americano. 'T Hoen (2003) chama a atenção para as discussões que tiveram lugar em Seattle e Doha. Essa mobilização teve como referência relevante a discussão em torno da disputa entre empresas farmacêuticas e o governo da África do Sul, relativa à suposta violação do Acordo TRIPS. A violação alegada decorreu em conseqüência da substituição por medicamentos genéricos daqueles medicamentos que, embora com patentes exauridas por findo o prazo de proteção, ainda eram vendidos pelas empresas que detiveram as respectivas patentes usando a figura da importação paralela; e exigir a transparência de preços para todos os medicamentos. A disputa em questão provocou duas importantes manifestações: uma de caráter legal, reconhecendo-se o direito dos países em desenvolvimento de fazerem uso das flexibilidades do Acordo TRIPS, e outra da relevância da pressão desses novos atores sociais, em especial as ONGs, sobre as empresas transnacionais farmacêuticas em seus países de origem, impondo-lhes custos sobre sua imagem (e suas vendas), de forma tal que as obrigou, pelo menos no curto prazo, a adoção de estratégias menos agressivas. Provocou ainda, e não menos importante, uma revisão das pressões, nos moldes em que estavam sendo feitas, pelo governo norte-americano.

$\mathrm{Na}$ reunião ministerial de Doha da Organização Mundial do Comércio (OMC), embora a questão da 
saúde pública e do acesso aos medicamentos não estivesse na agenda original, estas foram incorporadas à discussão. A existência de drogas protegidas na lista de medicamentos essenciais da Organização Mundial da Saúde (OMS) colocou o governo norte-americano sob a contestação dos ativistas de direitos humanos e mais especificamente dos defensores do acesso a medicamento por parte de doentes de aids. A África do Sul teve, por parte do governo dos Estados Unidos, uma posição de alento no discurso do presidente Clinton, em termos de revisão da política do Departamento de Comércio. De certa forma era criada a condição para a quebra do tabu da impossibilidade de aceitação norte-americana em termos da utilização do licenciamento compulsório para a utilização de genéricos para a distribuição em programas massivos para HIV positivos.

Essa situação, ainda segundo Hoen (2003), também foi decorrência de posições de organizações internacionais, cabendo ressaltar, além da já citada OMS, a Unaids (Organização das Nações Unidas para a AIDS), o Banco Mundial, o Grupo dos 77 (países em desenvolvimento que se articularam para defesa de seus interesses em relação aos constrangimentos propiciados pelo Acordo TRIPS) e, por fim, pelo acatamento da própria OMC de demandas dos países em desenvolvimento nesse ponto. O fato da Conferência Ministerial de Doha, em junho de 2001, não só discutir a questão, mas ainda ao seu fim ter uma Declaração sobre TRIPS e Saúde Pública, mostra o sucesso relativo da iniciativa.

Hoen (2003) mostra que o processo de negociação em Doha resultou num texto que reconhece o direito dos países em formular e executar políticas, assim como tomar medidas que garantam a proteção da saúde pública e o acesso da população aos medicamentos. Essas medidas podem ser tomadas a partir das flexibilidades do Acordo TRIPS. Entretanto, ficou pendente a questão pertinente à exportação para países que viessem a aplicar o licenciamento compulsório, mas que não possuíssem capacidade industrial para produzi-los. Ao não resolver esse ponto, o licenciamento compulsório, nos termos do TRIPS, tornar-se inócuo, já que o tratado se pronuncia, tão somente, à produção local para exercício do licenciamento compulsório.

É nesse contexto que se insere a política nacional de propriedade intelectual em saúde. Concomitante ao estabelecimento da nova legislação de propriedade intelectual, nos termos do Acordo TRIPS, todavia sem fazer uso das flexibilidades oferecidas pelo referido acordo, o Brasil se viu na circunstância de ter que adotar uma série de iniciativas para fazer frente à situação que criou com a legislação implementada no âmbito do Acordo.

Orsi et al. (2003) anotam que a decisão de garantia de acesso universal a todos os pacientes do vírus da aids ocorreu em 1996 (cabe lembrar que é o mesmo ano em que foi promulgada a nova legislação relativa à PI no Brasil) ${ }^{1}$. A legislação pertinente estabelecia, ainda, que para a concretização do programa, deveria ser seguida uma estratégia de redução de custo para que este fosse viável. Algumas restrições se impunham à época da formulação do programa. Uma delas dizia respeito às restrições derivadas do Acordo TRIPS, assinaladas anteriormente. Outra se relacionava à exigência que constava da legislação brasileira desde 1993 de licitações internacionais. Conjugada com o baixo incentivo propiciado à indústria farmacêutica nacional ${ }^{2}$, uma das conseqüências foi a utilização de importação de princípios ativos de países que, diferentemente do Brasil, tais como a China e a Índia, tinham tanto utilizado as flexibilidades do TRIPS quanto incentivado sua indústria farmacêutica.

A forma de superar tais constrangimentos foi fazer com que as novas drogas que viessem a compor o grupo de medicamentos a ser ministrado aos pacientes e que estivessem sob proteção intelectual deveriam ser compulsoriamente licenciadas e comercializadas como genéricos. Tal procedimento é compatível com o TRIPS, passível de utilização em situações de emergência nacional (a epidemia de aids pode ser incluída nesse rol) e de abuso econômico (Aded 2001, Dutfield 2001, Hasenclever 2004).

Outro constrangimento de ordem legal, todavia sem vinculação com o quadro internacional, dizia respeito à Lei Brasileira de Licitações (Lei 8666/93) que estabelece rigidez no processo de contratação governamental. No entanto, essa legislação contempla uma série de exceções que poderiam enquadrar a compra de medicamentos. Assim, se por um lado os constrangimentos derivados do aparato legal podiam ser superados, o acordo com a OMC que reduziu as tarifas de importação para fármacos, juntamente com a revisão da Lei 8666/93, que revogou a figura da preferência pela produção local e por empresas nacionais, criaram novos constrangimentos para a vinculação entre política de distribuição de medicamentos e incentivo ao desenvolvimento da indústria farmacêutica nacional (Orsi et al. 2003).

A efetivação do programa de distribuição de medicamentos no programa de aids teve como elemento central a participação de laboratórios oficiais. A redução nos preços dos medicamentos no período 1996-2001 foi da ordem de $75 \%$. Todavia, parte substantiva dessa redução deveu-se à importação de princípios ativos da Índia e China, de certa forma relegando a indústria farmacêutica nacional nesse processo. Igualmente relevante foi a participação da indústria farmacêutica multinacional nesse processo, já que participaram de licitações, oferecendo medicamentos protegidos a preços próximos dos que seriam praticados se fossem produzidos como genéricos.

Quanto ao mercado de medicamentos genéricos, de utilização fora do programa de distribuição gratuita e universal voltada para soropositivos, a participação da indústria farmacêutica nacional foi significativa. A política de genéricos do governo brasileiro teve como norte a ampliação do acesso aos medicamentos, fora dos programas oficiais de distribuição gratuita, por parte da população.

Hasenclever (2004) aponta para três principais impactos esperados em relação à política de genéricos: i - desconcentração da estrutura de mercado, pela maior participação dos medicamentos genéricos nas vendas da 
indústria farmacêutica; ii - redução do preço médio de venda propiciada pela maior concorrência entre medicamentos genéricos e os de marca, assim como entre os próprios medicamentos genéricos; e iii - ampliação das vendas de remédios, levando ao acesso da população, especialmente de menor poder aquisitivo. Utilizando dados do Instituto de Medicina Social (IMS) ${ }^{3}$ da Universidade Estadual do Rio de Janeiro (Uerj), e da Agência Nacional de Vigilância Sanitária (Anvisa) a autora mostra que as vendas de genéricos no mercado atacadista entre junho de 2000 e abril de 2001 cresceram 385\%, enquanto as vendas industriais cresceram em $114 \% 4$.

Hasenclever (2004) entende que os medicamentos genéricos impactaram significativamente a estrutura do mercado de medicamentos. Enquanto no período analisado os medicamentos de referência ${ }^{5}$ apresentaram declínio de 9,5 pontos percentuais (passaram de 73,4\% da parcela do mercado para $64,4 \%$ ) os medicamentos genéricos subiram 9,3 pontos percentuais (passando de $0 \%$ da parcela de mercado para $9,3 \%$ ). Um ponto relevante é que o impacto dos genéricos pareceu concentrar-se no segmento de medicamentos de referência, pois o mercado de similares não apresentou variações significativas no período. Em termos dos impactos previstos na política de genéricos, a redução do preço médio praticado é caudatária da desconcentração da estrutura de mercado. Igualmente verificou-se uma crescente inserção de medicamentos substitutos no mercado. A estratégia das empresas farmacêuticas tem sido a de manter os preços dos genéricos (em torno de $40 \%$ menor) em relação aos medicamentos de referência e, adicionalmente, não "forçar" os preços dos medicamentos de referência, inclusive pela pressão decorrente do controle de preços governamental. Salles Filho et al. (2001) indicam que parte da eficácia do controle de preços é decorrência da capacitação científica e tecnológica alcançada em instituições tais como a Fiocruz/Far-Manguinhos. A capacidade em apurar os custos de produção dos medicamentos de referência criou bases de negociação mais sólidas entre governo (Ministério da Saúde) e indústria farmacêutica.

Em relação às quantidades vendidas, Hasenclever (2004) mostra que o mercado de medicamentos como um todo, no período analisado, apresentou uma redução da ordem de 15\% nas quantidades vendidas, ressaltando ainda que nos segmentos nos quais os genéricos foram introduzidos, essa diminuição foi superior, chegando a pouco mais de $17 \%$. No entanto, o crescimento das quantidades vendidas de medicamentos genéricos aumentou em cinco vezes (superando os 600\%). A autora especula que parte do resultado apurado se deve à base de dados utilizada, assim como às estratégias adotadas pelas empresas líderes do mercado de medicamentos de referência. A concorrência dos medicamentos genéricos pode ter criado uma pressão de tal ordem que essas empresas líderes podem ter se concentrado em segmentos de mercado nos quais detém posição monopolistas e, conseqüentemente, menor pressão nas suas margens de lucro.

Outro ponto relevante do levantamento de Hasenclever (2004) diz respeito à participação das empresas nacionais no mercado de genéricos. Utilizando dados relativos ao registro de medicamentos genéricos, aponta 1.124 registros destes sob 4.448 apresentações em abril de 2004. Metade desses registros é de seis empresas nacionais, enquanto quatro multinacionais respondem por $18 \%$ dos mesmos. Os restantes 32\% dos registros de medicamentos genéricos são de diversos laboratórios com origem de capital igualmente diversa.

Pode-se considerar que a política de propriedade intelectual relativa a medicamentos apresenta duas vertentes com impactos e dinâmicas muito distintas. Nas duas vertentes a base da intervenção foi a capacitação técnica, científica e industrial nacional. No caso da distribuição de medicamentos que compõem a cesta ministrada universalmente e de forma gratuita pelo governo aos pacientes de aids, os laboratórios oficiais tiveram um papel preponderante, tanto em termos da capacidade de produção industrial dos medicamentos quanto em termos da regulação de preços. Qualquer política de propriedade intelectual estaria fadada ao fracasso sem essa capacidade industrial estatal, inclusive e principalmente para pressionar o setor privado.

Outro importante agente econômico no programa de produção de medicamentos para a cesta de aids foi a figura da empresa multinacional. A partir da base técnica, científica e industrial estatal foi possível um processo de negociação com a indústria farmacêutica multinacional de forma a que sua participação no programa, com medicamentos protegidos por patentes se fizesse de forma tal que não comprometesse a estratégia de redução de preços para a viabilização da distribuição universal e sua sustentabilidade. Nesse sentido, a possibilidade de utilização da figura do licenciamento compulsório opera como um mecanismo negocial, no qual a sua utilização concreta nem sempre é a melhor alternativa. Todavia, sem a perspectiva efetiva de utilização do licenciamento compulsório (que inclui a capacidade de copiar o medicamento e produzi-lo), essa negociação estaria fadada ao fracasso.

\section{Conclusão}

O mercado de medicamentos apresenta uma situação peculiar. Talvez valha insistir no ponto que diz respeito à manutenção de estruturas de $\mathrm{P} \& \mathrm{D}$ próprias ou em parcerias na indústria farmacêutica. Para entrar no mercado brasileiro, as empresas multinacionais não necessitam manter estruturas próprias. Ademais, como ressalta Nicolsky (2004), antes da Lei de Propriedade Industrial de 1996, a indústria nacional inovava o seu catálogo fabricando produtos similares, ou seja, cópias, modificadas ou não, dos produtos inovadores lançados no mercado externo e interno. Após 1997, quando a nova legislação entrou em vigor, o catálogo tradicional de medicamentos dos produtores nacionais passou a tender ao envelhecimento terapêutico pela impossibilidade da prática anterior de cópias, com exceção das existentes.

A política governamental de universalização de distribuição de medicamentos aos soropositivos no Brasil, por seu turno, não foi capaz de articular o desenvolvi- 
mento da indústria nacional, aí entendida como empresas privadas de capital nacional, a partir de um programa massivo de compras governamentais. Nesse ponto vale recordar que a lógica de negociação da legislação de PI, que resultou na atual legislação, foi altamente regressiva no que diz respeito à indústria e ao interesse nacional. Ao abrir mão das flexibilidades oferecidas pelo Acordo TRIPS, especialmente na possibilidade de se obter até dez anos para o reconhecimento de novas drogas, chegando até mesmo a adotar o estatuto do pipeline, o país viu inviabilizada a produção local de princípios ativos pela indústria nacional

Num certo sentido, a situação criada foi inusitada. Para contornar os obstáculos propiciados pela legislação adotada, o país se viu na contingência de estabelecer uma política de propriedade intelectual na área de medicamentos para superar esses constrangimentos criados por ele próprio. Se a política de propriedade intelectual mostrou sinais inequívocos de êxito no que tange à produção e distribuição de medicamentos, esse êxito está fortemente ligado à capacidade dos laboratórios estatais e à posição incisiva nas negociações internacionais que se seguiram à decisão de produção de medicamentos patenteados como genéricos. Ironicamente algo que talvez não tivesse sido necessário com a adoção de uma legislação de PI menos restritiva e dentro do previsto no Acordo TRIPS.

Cabe, ainda, assinalar que na política de propriedade intelectual relativa aos genéricos vendidos fora do programa de aids, as empresas nacionais encontraram um nicho importante, no qual apresentam competitividade e conseguem fazer frente às empresas estrangeiras. No entanto, essa competitividade é fortemente dependente da importação de princípios ativos de países como a Índia e a China que utilizaram as flexibilidades do Acordo TRIPS, no sentido de prorrogarem por dez anos o reconhecimento de novas drogas.

Entende-se que as negociações que se seguiram à Rodada de Doha da OMC, não apresentam um quadro dos mais promissores para se dar continuidade à política de propriedade intelectual adotada pelo Brasil. As melhores possibilidades em termos de obrigação de produção local esbarram na posição dos países em desenvolvimento, especialmente na negociação do Acordo de Medidas Relacionadas à Produção Local (TRIM) (Carta de Genebra, diversos números). Os países desenvolvidos entendem que as melhores medidas de incentivo à produção local são aquelas relativas a um sistema forte de proteção à propriedade intelectual, que, pela experiência brasileira, não são exatamente as que melhor atendem aos interesses nacionais (aí incluídas as empresas de capital nacional)

Antes de concluir, caberia ressaltar que, apesar das contradições da política adotada, ela foi capaz de responder aos desafios impostos pela legislação de PI. O país conseguiu superar grande parte dos constrangimentos, transformando-os em oportunidades de desenvolvimento industrial. Essas oportunidades, entretanto, não serão sustentáveis ao longo do tempo sem uma clara articulação entre política de PI e de inovação, centrada na amplia- ção da competência e capacitação da empresa privada nacional, na manutenção da excelência dos laboratórios estatais e, principalmente, na criação de estímulos, sejam de caráter indutivo, sejam de caráter impositivo, às empresas farmacêuticas internacionais, para que articulem parte do seu esforço em $\mathrm{P} \& \mathrm{D}$ à estrutura científica e tecnológica nacional. Sem sombra de dúvida, os instrumentos de proteção à propriedade intelectual jogarão um papel central nesse processo.

\section{Notas}

1. Todavia, desde 1988, num processo no qual ONGs tiveram grande importância, por determinação do Ministério da Saúde, a distribuição do primeiro medicamento (AZT) eficaz para ampliação da vida dos soropositivos deveria ser feito pela rede pública de posto e hospitais credenciados.

2. Nunca é demais lembrar o contexto de liberação comercial do início da década de 1990 e o do próprio TRIPS.

3. A autora aponta diversos vieses na análise baseada em dados do IMS. Estima que no período de apuração, entre junho de 2000 e abril de 2001, apenas 48\% das vendas de genéricos foram captadas. Implica que há uma subestimação da participação dos medicamentos genéricos no mercado a partir da referida base de dados.

4. As diferenças de crescimento se devem ao impacto maior decorrente da pressão governamental sobre compras que faz impondo a utilização de genéricos para o mercado atacadista e dependência de adesão do consumidor e do prescritor (médico) ao medicamento genérico, seja pela substituição do medicamento de marca, seja pela inclusão de novos consumidores.

5. Medicamentos de referência são aqueles protegidos por patentes e comercializados por uma marca. Os medicamentos similares são aqueles cujas patentes estão expiradas ou em domínio público e podem ser comercializados por marca ou sem marca.

\section{Referências bibliográficas}

Aded AO. The political economy of the trips agreement: origins and history of negotiations dialogue at the Aberdare Country Club in Kenya, 30-31 July 2001, under the sponsorship of The International Centre for Trade and Sustainable Development (ICTSD) and the African Centre for Technology Studies (ACTS) in collaboration with the Quaker United Nations Office (QUNO); 2001.

Barbosa ALF. Sobre a propriedade do trabalho intelectual: uma perspectiva crítica. Rio de Janeiro: Editora UFRJ; 1999.

Buainain AM, de Carvalho SMP, Paulino SR, Yamamaura S. Propriedade intelectual e inovação tecnológica: algumas questões para o debate atual. In: O futuro da indústria: cadeias produtivas. Brasília, MDIC:IEL Nacional; 2004 (disponível em: www.desenvolvimento.gov. $\mathrm{br} /$ tecnologia/ revistas/revColetanea6.htm) 
Carta de Genebra. Informativo sobre a OMC e a Rodada de Doha. Ministério das Relações Exteriores: Genebra, diversos números.

Carvalho SMP. Propriedade intelectual na agricultura. [Tese de Doutorado] Instituto de Geociências, Universidade Estadual de Campinas, DPCT/IG/Unicamp; 2003.

Carvalho SMP, Pessanha LDR. Propriedade intelectual, estratégias empresariais e mecanismos de apropriação do esforço de inovação no mercado brasileiro de sementes. Rev Econ Contemp. 2001; jan./jun. 5(1):151-182.

Carvalho SPM, Yamamura S, Machado G, Buainain AM. Tendências focalizadas em propriedade intelectual, transferência de tecnologia e informação tecnológica no Brasil. Campinas, Macroplan/INPI: GEOPI/Unicamp, 2002a.

Carvalho SPM, Yamamura S, Machado G, Buainain AM. Tendências focalizadas em propriedade intelectual, transferência de tecnologia e informação tecnológica no Brasil. In: Anais do XXII Simpósio de Gestão da Inovação Tecnológica. Salvador, 6 a 8 de novembro: 2002b.

Coriat B. O novo regime global de propriedade intelectual e sua dimensão imperialista: implicações para as Relações "Norte/Sul”. In: Desenvolvimento em debate: novos rumos do desenvolvimento no mundo. Castro AC, organizadora. Rio de Janeiro, Mauad: BNDES; 2002. p. 375-96.

Coriat B, Dumoulin J, Flori Y-A, Barnett T, Souteyrand Y, Moatti J-P. Patents, Generic Drougs and the Market for Antiretrovirals. In: Moatti J-P, Coriat B, Souteyrand Y, Barnett T, Dumoulin J, Flori Y-A, editors. Economics of AIDS and access to HIV/AIDS care in developing countries: issues and challenges. Paris: anRs/Le Publier; 2003 (ANRS, Collection Sceinces Sociales et Sida).

Dutfield G. Intellectual porperty rights and development. Genebra: UNCTAD/ICTSD; 2001 (versão preliminar): p. 4-14.
Hasenclever L. O mercado de medicamentos genéricos no Brasil. In: Seminário Franco-Brasileiro a propriedade intelectual no domínio da saúde: aspectos econômicos, jurídicos e legislativos. Brasília: 22- 24 de junho 2004. Disponível em: www.aids.gov.br. Acessado em: 16 de agosto 2004.

Hoen EFM. TRIPS, Pharmaceutical patents and access to essential medicines: from Seattle to Doha and Beyond. In: Moatti J-P, Coriat B, Souteyrand Y, Barnett T, Dumoulin J, Flori Y-A, editors. Economics of AIDS and access to HIV/AIDS care in developing countries: issues and challenges. Paris: anRs/Le Publier; 2003 (ANRS, Collection Sceinces Sociales et Sida).

Juma C. Intellectual property rights and globalization: implications for developing coutries. Science, technology and innovation discussion Paper no. 4. Cambridge, MA, USA: Center for International Development, Harvard University; 1999.

Nicolsky R. Política de fomento à inovação na indústria farmoquímica-farmacêutica. In: Seminário Franco-Brasileiro a propriedade intelectual no domínio da saúde: aspectos econômicos, jurídicos e legislativos. Brasília: 22-24 de junho 2004. Disponível em: www.aids.gov.br. Acessado em: 16 de agosto 2004.

OECD. Public/private partnerships in science and technology: an overview Background. Introduction: STI Review No. 23; 1999.

Orsi F, Hasenclever L, Fialho B, Tigre P, Coriat B. Intellectual property rights, anti-AIDS policy and generic drugs: lessons from the Brazilian public health program. In Moatti J-P, Coriat B, Souteyrand Y, Barnett T, Dumoulin J, Flori Y-A, editors. Economics of AIDS and access to HIV/AIDS care in developing countries: issues and challenges. Paris: anRs/Le Publier; 2003 (ANRS, Collection Sceinces Sociales et Sida).

Salles-Filho S, Paulino S, Carvalho SMP. Reorganização em instituições públicas de pesquisa: Embrapa e Fiocruz. Cad Ciên Tecnol. 2001; 18(3):11-38.

\section{Sobre os autores}

\section{Sérgio M. Paulino de Carvalho}

Sérgio Paulino de Carvalho é Economista, formado pela Universidade Federal Fluminense, e doutor em política científica e tecnológica, pela Unicamp, é o Diretor de Articulação e Informação Tecnológica do INPI

\section{Sérgio Salles-Filho}

Sergio Salles-Filho é Engenheiro Agrônomo e doutor em Economia. Atualmente é professor titular do Depto de Politica Científica e Tecnológica da UNICAMP onde trabalha com temas relacionados a planejamento e gestão de tecnologia e inovação. 